\title{
Water Vapour Storage Capacity of Masonry Renovation Plasters Contaminated with Chlorides
}

\author{
Milena PAVLÍKOVÁ ${ }^{1}$, Zbyšek PAVLÍK ${ }^{1 *}$, Peter MATIAŠOVSKÝ ${ }^{2}$ \\ ${ }^{1}$ Faculty of Civil Engineering, Czech Technical University in Prague, Thákurova 7, 16629 Prague, Czech Republic \\ ${ }^{2}$ Institute of Construction and Architecture, Slovak Academy of Sciences, Dúbravská cesta 9, 84503 Bratislava, Slovak \\ Republic
}

crossref http://dx.doi.org/10.5755/j01.ms.24.4.19434

Received 08 November 2017; accepted 26 December 2017

\begin{abstract}
The effect of sodium chloride presence on the water vapour storage capacity was studied for six types of plasters designed for application in masonry restoration. Sorption isotherms were measured using a static climate chamber method. The researched materials were characterised by their bulk density, matrix density, and total open porosity. For the studied materials, measurement of chloride binding isotherms by an adsorption method was done in order to reveal their capacity to accumulate salts and relate the adsorbed water vapour to the amount of contained salt. The experimental sorption data measured for salt contaminated samples were analysed using relation expressing the dependence of the mass equilibrium moisture content (EMC) of plasters saturated with salt solution of given molality on relative humidity of the environment. For relative humidity up to $70 \%$, good agreement between measured and calculated data was obtained. For higher relative humidity, the water vapour adsorption capacity of studied materials was not fully exploited especially for lower chloride concentrations. The type of binder together with physical parameters of examined materials was found to have a decisive role in chloride binding. One of the tested materials can be possibly classified as WTA renovation plaster, considering its total open porosity, bulk density and high binding capacity for chlorides. On the other hand, one must take into account its hygroscopicity, especially in case of a higher salt contamination.

Keywords: water vapour storage capacity, renovation plasters, salt contamination, chloride binding isotherms.
\end{abstract}

\section{INTRODUCTION}

Hygroscopic moisture content (HMC) of porous building materials is of a particular importance for their save and effective application in practice. Except parameters of material structure as specific surface, pore size distribution, pores connectivity, and chemical basis, material environmental exposure significantly affects HMC values. Here, ambient relative humidity $(\mathrm{RH})$ and temperature are the decisive variables having clear relation to the rate of water vapour storage in porous body. Material ability to accumulate water vapour molecules is usually characterized by sorption isotherms that are the graphic representation of the dependence of material HMC on RH of the environment at equilibrium condition, i.e. the $\mathrm{RH}$ inside of the material is equal to that of external [1].

Several studies were conducted on measurement of sorption isotherms of building materials up to now. For example, Hansen [2] published comprehensive sorption isotherms catalogue with more than 100 sorption plots. Kumaran introduced a thermal and moisture property database for common building and insulation materials that was result of ASHRAE Research Project 1018 [3]. More recently, McGreggor et al. [4] studied the moisture buffering capacity of unfired clay masonry and measured sorption isotherms of 21 different kaolinite and montmorillonite type clay minerals. Vololonirina et al. [5] measured sorption and desorption isotherms of woodbased products as OSB, wood fibre insulation, and solid

\footnotetext{
* Corresponding author. Tel.: +420-224-354-371.

E-mail address: pavlikz@fsv.cvut.cz.(Z.Pavlík)
}

wood (spruce). The studied wood-based materials were found to be highly hygroscopic and exhibited small hysteresis. The above given examples of sorption isotherms were measured above all in order to characterize the researched materials or to get input material data for the computational modelling of moisture transport. However, an incorporation of other effects having clear impact on the water vapour storage capacity was mostly not introduced.

As stated above, the adsorption and desorption processes closely depend on the external and internal conditions of material such as temperature, moisture content, salt content, etc. Temperature dependence of sorption process studied e.g. Wortmann et al. [6] who measured sorption plots for wool. Authors referred on approx. $20 \%$ decrease in the maximum HMC measured at $100{ }^{\circ} \mathrm{C}$ contrary to data accessed at $20{ }^{\circ} \mathrm{C}$. Wu et al. [1] measured sorption isotherms of the hardened cement pastes at $25^{\circ} \mathrm{C}, 33{ }^{\circ} \mathrm{C}$, and $40{ }^{\circ} \mathrm{C}$ respectively. The general trend as reported in the literature was also found for the three cement pastes studied, i.e., the higher the temperature, the less the amount of adsorbed water. The effect of temperature on sorption isotherms of materials on cement basis was investigated also in [7]. Considering the above given survey on the analyses of the temperature effect on HMC values one can see that this phenomenon is of a high research interest. On the other hand, there is only weak information on the effect of salt contamination on materials vapour storage capacity. In real conditions of building, interaction of inbuilt materials with water and dissolved chemicals is frequent, especially in materials of historical masonry and materials exposed to the exterior 
environment. Although it is generally accepted that the salt presence increases HMC in a material body, the effect of salt presence on water vapour storage capacity of building materials was studied only rarely. One of the exceptions is work published by Koronthalyova at al. [8] who reported on the existence of a linear relation between the HMC and salt concentration in ceramic brick. However, in the range of high RH values, the linear relation between HMC and salt content of brick can only be expected for bricks with similar hygroscopic ability as contained salt. Hygroscopic behaviour of Dutch red brick contaminated with salts was investigated by Lubelli at al. [9] who studied hygroscopic performance of $\mathrm{NaCl}, \mathrm{Na}_{2} \mathrm{SO}_{4}$, and $\mathrm{NaNO}_{3}$, considered as single salts or combined in a mixture. The results of this study can be useful to building practice, because it has been verified that when the type of salty elements are known, it is possible to obtain an indication of the salt content on the basis of HMC measurement.

In order to extend current state of knowledge in the field of water vapour sorption capacity of building materials contaminated with salts, the effect of sodium chloride presence on vapour storage capacity of six types of plasters designed for reconstruction and renovation works is experimentally quantified in order to verify their applicability on salt laden masonry. For the studied materials, measurement of chloride binding isotherms by adsorption method is done in order to reveal their capacity to accumulate salts that can be potentially transported from the substrate. The measured sorption isotherms are theoretically analysed and the mechanisms of vapour storage and chloride accumulation in studied materials are discussed.

\section{STUDIED MATERIALS}

Four different types of lime-based plasters and two cement-lime plasters were prepared. The composition of tested plasters (see Table 1 and Table 2) was designed in order to imitate lime plasters, which were used hundred years ago.

Table 1. Composition of researched plasters

\begin{tabular}{|l|c|c|c|c|c|}
\hline Plaster & $\begin{array}{c}\text { Water, } \\
\mathrm{kg}\end{array}$ & $\begin{array}{c}\text { Lime } \\
\text { hydrate, } \\
\mathrm{kg}\end{array}$ & $\begin{array}{c}\text { Metakaolin, } \\
\mathrm{kg}\end{array}$ & $\begin{array}{c}\text { Zinc } \\
\mathrm{st.}, \\
\mathrm{kg}\end{array}$ & $\begin{array}{c}\text { Sand } \\
0 / 2 \mathrm{~mm}, \\
\mathrm{~kg}\end{array}$ \\
\hline VO & 4.8 & 4.8 & - & - & 14.4 \\
\hline VOM & 5.5 & 4.8 & 1.2 & - & 14.4 \\
\hline VOMII & 4.2 & 4.0 & 0.8 & - & 14.4 \\
\hline VOMH & 4.8 & 4.0 & 0.8 & 0.02 & 14.4 \\
\hline
\end{tabular}

Table 2. Composition of researched plasters

\begin{tabular}{|c|c|c|l|}
\hline Plaster & $\begin{array}{c}\text { Water, } \\
\mathrm{kg}\end{array}$ & $\begin{array}{c}\text { Dry } \\
\text { mixture, } \mathrm{kg}\end{array}$ & \multicolumn{1}{c|}{ Composition of dry mixture } \\
\hline VOC & 7.2 & 40 & $\begin{array}{l}\text { Trass, cement, lime hydrate, } \\
\text { dolomitic sand, admixtures }\end{array}$ \\
\hline VOS & 6.3 & 35 & $\begin{array}{l}\text { Trass, lime hydrate, cement, } \\
\text { sand, admixtures }\end{array}$ \\
\hline
\end{tabular}

In order to improve plasters durability, but keep the chemical composition and basic material properties similar to the original historical plasters, the lime hydrate was partially substituted by metakaolin. There was in the first case added metakaolin to lime plaster denoted as VOM, and in the second case lime was partially replaced by metakaolin, plaster labelled as VOMII. The third plaster, denoted as VOMH, had the same composition as VOMII but contained hydrophobic admixture on the zinc stearate basis. Metakaolin MEFISTO K05 was delivered by company “České lupkové závody Inc.”, Nové Strašecí. It is a highly active pozzolana material on a metakaolinite basis with average particle size from 3 to $5 \mu \mathrm{m}$. The other two investigated plasters were based on commercially produced dry mixtures, namely cement-lime basecoat plaster (VOC), and renovation plasters denoted VOS with hydrophobic admixture. For the comparison, it was measured also pure lime plaster VO.

The used lime hydrate CL90 was produced by limekiln Mokrá, Czech Republic. The silica aggregate of fraction 0/2 $\mathrm{mm}$ was produced by Heidelberg Cement Group, Brněnské písky Inc., affiliate Bratčice. It was used in the modified lime plasters and pure lime plaster only. Commercially produced plasters mixtures had aggregate of fraction $0 / 4 \mathrm{~mm}$. The water dosage was slightly modified in order to keep the workability of fresh mixtures on the same level.

The prismatic samples having dimensions of $20 \times 20 \times 10 \mathrm{~mm}$ were manufactured. The particular samples were covered by PE foil for 48 hours to reach a sufficient strength. After this period the specimens were unmoulded, placed into plastic containers and covered with PE foil. The tested samples were cured with everyday water spraying for 26 days in a laboratory environment at $23 \pm 2{ }^{\circ} \mathrm{C}$. Then they were dried in a vacuum oven at $60^{\circ} \mathrm{C}$ to reach an equilibrium mass. After that always ten samples were immersed in $0.5 \mathrm{M}, 1 \mathrm{M}, 1.5 \mathrm{M}$, and $2.5 \mathrm{M}$ $\mathrm{NaCl}$ solution for half a year. Samples were then removed from the solutions, wiped and finally dried in a vacuum oven at $60{ }^{\circ} \mathrm{C}$ to reach an equilibrium mass.

\section{EXPERIMENTAL}

Bulk density, matrix density, and open porosity of examined plasters were determined. The bulk density was measured using gravimetric method according to EN 1015-10. The expanded relative uncertainty of the bulk density test was $2.3 \%$. The matrix density was obtained using Pycnomatic ATC (Thermo Scientific), automatic helium pycnometer. The open porosity was then simply calculated. The relative expanded uncertainty of the applied testing methods was about $3.6 \%$.

The measurement of sorption isotherms was done on a gravimetric principle. For the measurement, climatic chamber that allows expose the studied samples to specific relative humidity at constant temperature was used. Relative humidity was stepwise increased from $10 \%$ to $95 \%$. The temperature was set to $23{ }^{\circ} \mathrm{C}$. The mass of samples was measured in specific time periods until the steady state value of mass for one RH step was achieved. Then, the mass equilibrium moisture content (EMC) was calculated according to the Eq. 1:

$$
E M C=\frac{m_{w}-m_{d}}{m_{d}}
$$

where $m_{w}(\mathrm{~kg})$ is the mass of wet sample and $m_{d}(\mathrm{~kg})$ is the mass of dry sample. The EMC (-; kg/kg) corresponding to 
the one simulated $\mathrm{RH}$ value was calculated as an average from the measurement of 10 samples for the particular researched material.

The chloride binding isotherms were measured using the equilibrium adsorption method from solution [10]. In our experiments, the particular samples were placed into the plastic cups with $200 \mathrm{ml}$ chloride solution of exact concentration, whereas five samples for each chloride concentration were used. The cups were stored in a climate chamber at the temperature of $23 \pm 2{ }^{\circ} \mathrm{C}$ to achieve equilibrium. The inside solutions were analysed at first after six months, then three times in two days period to verify the measurement reproducibility and equilibrium of chloride concentration. The content of chlorides in solution was accessed on potentiometry principle using device inoLab $740 \mathrm{pH} /$ Ion equipped with chloride ion selective electrode (ISE). From the measured data the bound chloride content $C_{b}\left(\mathrm{mg} / \mathrm{g}_{\text {sample }}\right)$ and free chloride content $C_{f}\left(\mathrm{mg} / \mathrm{l}_{\text {solution }}\right)$ were calculated and one point of chloride binding isotherm was obtained. The bound chloride content $C_{b}$ was calculated from the Eq. 2:

$C_{b}=\frac{M_{C l} V\left(C_{0}-C_{1}\right)}{W}$,

where $M_{\mathrm{Cl}}(\mathrm{g} / \mathrm{mol})$ is the molar mass of chlorine, $V(\mathrm{ml})$ the volume of the solution, $\mathrm{C}_{0}, \mathrm{C}_{1}(\mathrm{~mol} / \mathrm{l})$ the initial and equilibrium concentrations, respectively, of chloride solution and $W(\mathrm{~g})$ the mass of the dry sample. The free chloride content $C_{\mathrm{f}}$ corresponding to the value of $C_{\mathrm{b}}$ was given as $C_{f}=C_{1}$. By performing the experiments with different values of the initial chloride concentration in solution $C_{0}$, a point wise function $C_{b}=C_{b}\left(C_{f}\right)$ was obtained, which was the ion binding isotherm [10].

\section{DATA ANALYSIS}

The experimental sorption data measured for salt contaminated samples were analysed using relation expressing the dependence of the mass equilibrium moisture content of plasters saturated with salt solution of given molality on $\mathrm{RH}$ of the environment. For relative humidity $\varphi(-)$ lower than humidity over the salt saturated solution, the hygroscopic moisture content fixed by salt $u_{c}$ $(\mathrm{kg} / \mathrm{kg})$ was expressed as

$u_{c}=s\left(\frac{1}{c_{s}}-1\right)$

where $c_{s}$ is the concentration of the saturated salt solution. In our case, we considered at $25{ }^{\circ} \mathrm{C}$ concentration of the saturated $\mathrm{NaCl}$ solution of $0.36 \mathrm{~kg} / \mathrm{kg}$ [11]. For relative humidity $\varphi(-)$ higher than $\mathrm{RH}$ over the saturated salt solution, i.e. for $\mathrm{RH}$ above the deliquescence relative humidity, the hygroscopic moisture content fixed by salt was expressed as

$u_{c}=\frac{s\left(1-\varphi_{s}\right)}{c_{s}(1-\varphi)}$

where $\varphi_{s}=0.75$ is the $\mathrm{RH}$ over the saturated $\mathrm{NaCl}$ solution [11]. The salt content $s(\mathrm{~kg} / \mathrm{kg})$ in material is formulated in Eq. 5. $s=\frac{m_{s}-m_{d}}{m_{d}} c$

where $m_{s}(\mathrm{~kg})$ is the mass of salt solution saturated sample, $m_{d}(\mathrm{~kg})$ is the mass of dry sample, and $c(\mathrm{~kg} / \mathrm{kg})$ is the concentration of $\mathrm{NaCl}$ solution.

Summarizing the above given formulas and considering Eq. 1, the total moisture content $u_{t}(\mathrm{~kg} / \mathrm{kg})$ of a salt contaminated material at given RH was expressed as

$u_{t}=u_{m}+s+u_{c}=E M C$,

where $u_{m}(\mathrm{~kg} / \mathrm{kg})$ is the moisture content adsorbed by pure material without salt, $s$ the salt content, and $u_{c}$ is the moisture content fixed by salt. In case of non-hygroscopic materials, the equilibrium moisture content is limited from bellow by the RH over the saturated salt solution $\left(\varphi_{s}\right)$. However, in hygroscopic materials, saturated salt solution occurs in pores even at lower RH. This behaviour shows the metakaolin containing plasters and slightly renovation plaster with hydrophobic admixture VOS. On this account, $u_{c}$ values given by Eq. 3 are continuously reduced with decreasing relative humidity. In Table 3, there are presented values of these reductions that we obtained for particular chosen materials within the sorption isotherm tests performed at $\mathrm{RH}<0.75$. From above, the equilibrium moisture content is limited by the capillary saturation.

Table 3. $u_{c}$ values reductions obtained from sorption tests

\begin{tabular}{|c|c|c|c|c|}
\hline Plaster & VOM & VOMII & VOHM & VOS \\
\hline $70 \% \mathrm{RH}$ & 1.0 & 1.0 & 1.0 & 0.3 \\
\hline $50 \% \mathrm{RH}$ & 0.7 & 0.9 & 0.7 & 0.1 \\
\hline
\end{tabular}

\section{RESULTS AND DISCUSSION}

Basic physical properties of studied plasters are given in Table 4. The tested materials exhibited high total open porosity, whereas an application of hydrophobic agent led to its increase by about $40 \%$ in the comparison with other two VOM mixtures. According to the WTA directive 2-9-04 (WTA Scientific-Technical Association for Building Maintenance and Monument Preservation), the value of the total open porosity of renovation mortar must be $>40 \%$. This requirement met VOMH, VOS, and VOC taking into account the measurement uncertainty. However, the WTA requires also bulk density values $<1400 \mathrm{~kg} / \mathrm{m}^{3}$. From this point of view, only VOS plaster can be possibly classified as WTA renovation plasters, whereas also other additional requirements must be met.

Table 4. Basic physical properties of studied plasters

\begin{tabular}{|l|c|c|c|}
\hline Plaster & $\begin{array}{c}\text { Bulk density, } \\
\mathrm{kg} / \mathrm{m}^{3}\end{array}$ & $\begin{array}{c}\text { Matrix density, } \\
\mathrm{kg} / \mathrm{m}^{3}\end{array}$ & $\begin{array}{c}\text { Total open } \\
\text { porosity, } \%\end{array}$ \\
\hline VO & 1650 & 2605 & 36.7 \\
\hline VOM & 1670 & 2570 & 35.0 \\
\hline VOMII & 1695 & 2580 & 34.0 \\
\hline VOMH & 1745 & 2615 & 49.9 \\
\hline VOC & 1545 & 2555 & 39.5 \\
\hline VOS & 1175 & 2555 & 54.6 \\
\hline
\end{tabular}

Fig. 1 -Fig. 6 show experimentally measured sorption isotherms (points) together with data calculated using theoretical procedure described above (lines). Here, also 
the theoretically derived moisture content values corresponding to $100 \% \mathrm{RH}$ are also presented respecting the maximum capillary moisture content.

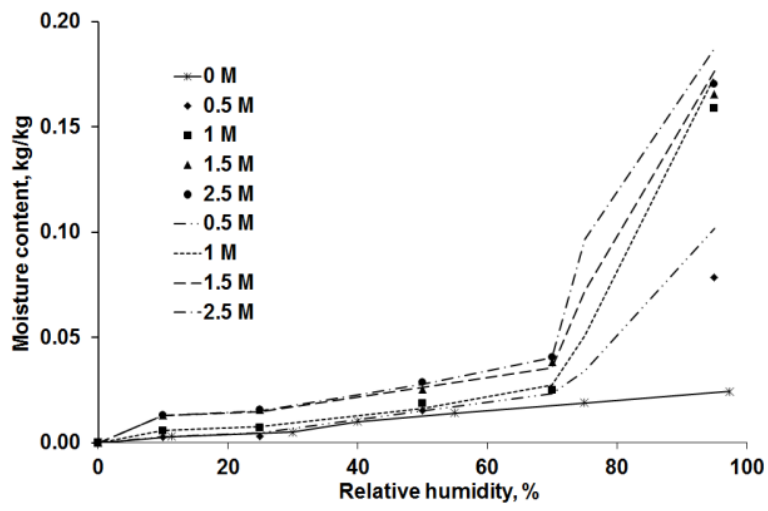

Fig. 1. Experimental and theoretically derived sorption isotherms

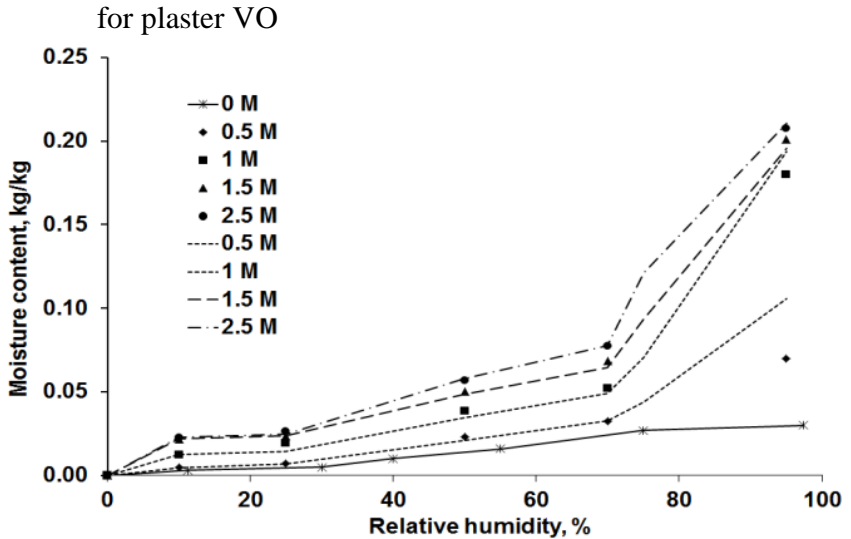

Fig. 2. Experimental and theoretically derived sorption isotherms

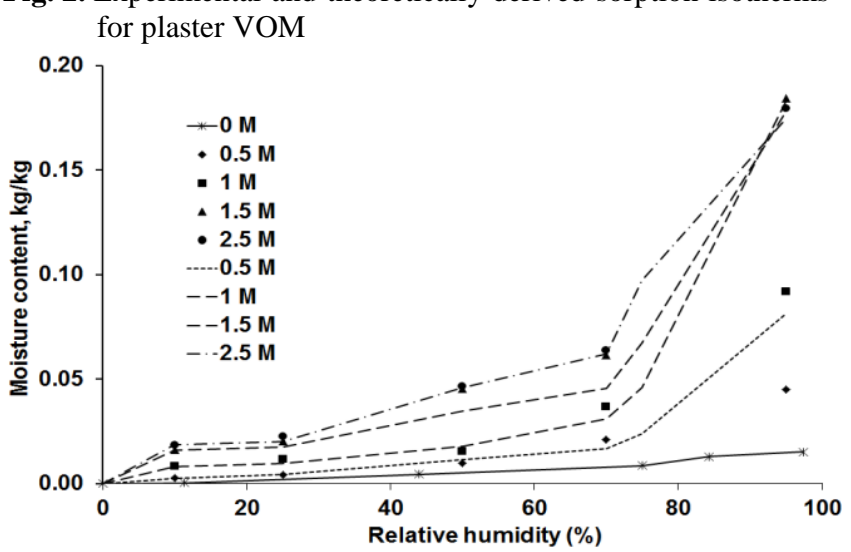

Fig. 3. Experimental and theoretically derived sorption isotherms for plaster VOMII

The maximum EMC values measured for reference plaster samples varied from approx. $0.015 \mathrm{~kg} / \mathrm{kg}$ for VOMH to $0.03 \mathrm{~kg} / \mathrm{kg}$ for VOM. This data is in agreement with results published by Moropoulou at al. [12] who researched a drying kinetics of different types of building materials. They measured for cement based plaster maximal EMC around $0.02 \mathrm{~kg} / \mathrm{kg}$ what corresponds with the maximum EMC of cement-lime plaster VOC.

Although an application of zinc stearate led to the significant increase in the total open porosity of plaster VOMH compared to the plasters VOM and VOM, its water vapour adsorption capacity was the lowest due to the hydrophobic effect that changed the contact angle among the material surface and water molecules.

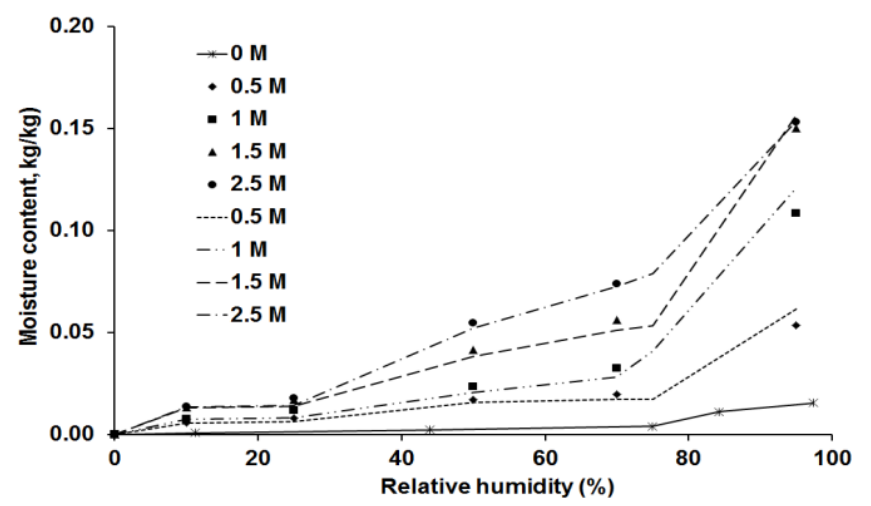

Fig. 4. Experimental and theoretically derived sorption isotherms for plaster $\mathrm{VOMH}$

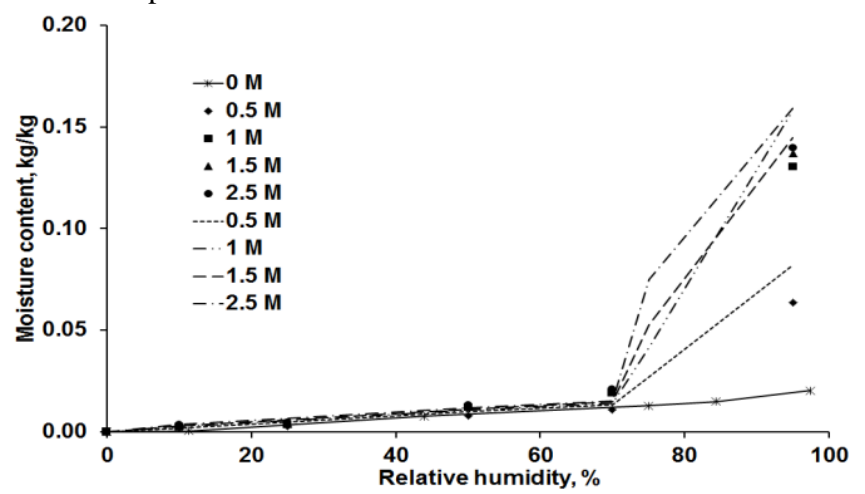

Fig. 5. Experimental and theoretically derived sorption isotherms

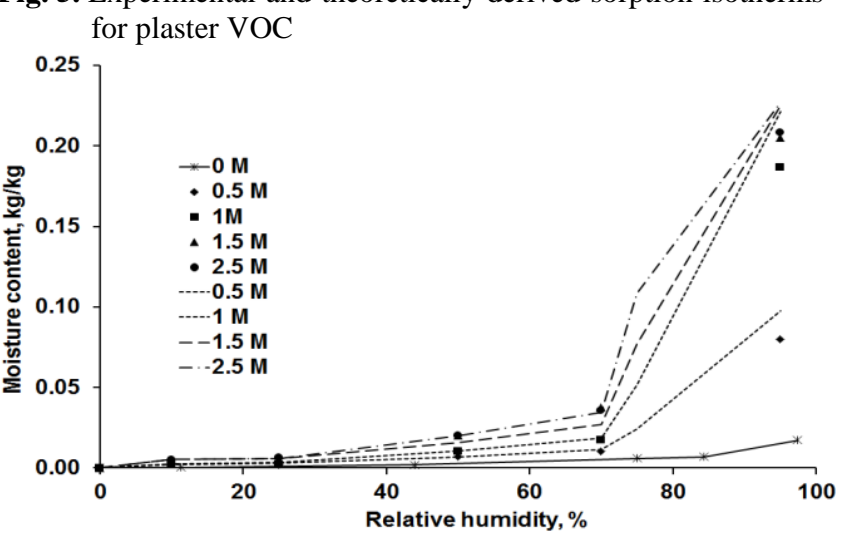

Fig. 6. Experimental and theoretically derived sorption isotherms for plaster VOS

Looking at the sorption isotherms of salt laden plasters, one can see a significant effect of salt content on materials water vapour adsorption capacity. The highest adsorption capacity was observed for renovation plaster VOS having maximum of sorption isotherm at $0.21 \mathrm{~kg} / \mathrm{kg}$. It was more ten times higher than in the case of reference VOS samples without salt. However, all the studied plasters exhibited substantially higher adsorption capacity due to the salt presence. In case of plasters containing cement, the effect of salt content on the adsorption capacity was remarkable for higher RH values only, typically from RH $>0.7$. Similar feature observed Koniorczyk and Wojciechowski [13] that measured desorption isotherm of cement mortar samples exposed to $\mathrm{NaCl}$ solution. On the other hand, lime plaster and especially plasters based on lime-metakaolin blend exhibited influence of salt content on EMC values in the whole studied RH range. Nevertheless, also in this case, the effect of salt content was more significant for higher 
RH, typically from approx. $70 \%$. The plasters behaviour for $\mathrm{RH}>0.7$ we assign to the deliquescence point of $\mathrm{NaCl}$. In this case, physically solely the surfaces of the salt crystals interact with humidity, and at a certain point of RH dissolution of salt in water occurs. From a chemical point of view, saturated salt solution coexists with salt crystals and deliquescence humidity which is for $\mathrm{NaCl}$ system approx. $0.75(-)$. For RH higher than the deliquescence humidity, distinct increase in the adsorbed moisture content was identified for all studied plasters as a consequence of $\mathrm{NaCl}$ behaviour at high $\mathrm{RH}$. This is in agreement with data published by Price [14]. He investigated hygroscopic behaviour of mortar drillings from the Wakefield Tower, Tower of London, in order to predict environmental conditions that would minimize salt damage to the interior stonework. Moisture content of almost all samples showed a marked increase between $66 \%$ and $77 \% \mathrm{RH}$, whereas much of the absorption took place at the top end of this range, as the equilibrium $\mathrm{RH}$ of $\mathrm{NaCl}$ is $75 \%$ and for $\mathrm{NaNO}_{3}$ it is $76 \%$.

Comparing the experimental data and data calculated based on the theoretical considerations stated above, good agreement between sorption curves was obtained in the whole studied $\mathrm{RH}$ range taking into consideration the measuring uncertainty, salt distribution in studied specimens and many other material and experimental factors. Except for EMC corresponding to the highest RH value, the theoretically derived model for sorption capacity of salt laden materials was found to be applicable for estimation of sorption isotherms of porous building materials on silicate basis. In case of a low salt contamination, the theoretical equilibrium moisture content corresponding to $\mathrm{RH}$ of $95 \%$ was not reached within the performed experiments. We assume the time necessary to acquire the equilibrium mass was in this case longer than the duration of the sorption test. On the other hand, for samples exposed do $1.5 \mathrm{M}$ and $2.5 \mathrm{M}$ solutions, the EMC was reached. It gave notice of the difference in binding velocities and adsorption kinetics of water vapour molecules on the silicate structure and inorganic salt [15]. In case of materials highly contaminated by salt presence, reduced number of sites accessible for water vapour is present due to the partial filling of porous space by salt. On this account, the water vapour adsorption by hygroscopic salt is dominant. As material contains low amount of salt only, the adsorption by the silicate material basis is of the particular importance.

Measured chloride binding isotherms are presented in Fig. 7. The highest binding capacity for chlorides $(20.0 \mathrm{mg} / \mathrm{g})$ yielded plaster VOS that thus proved its applicability in renovation of salt laden masonry. However, also plaster VOM accumulated high amount of chlorides that was around $19.5 \mathrm{mg} / \mathrm{g}$. Similar binding capacity obtained, e.g., de Weerdt et al. [16] who analysed the impact of sulpate and magnesium on chloride binding in Portland cement paste. The authors referred on binding capacity of chlorides ranging from around $5 \mathrm{mg} / \mathrm{g}$ to $21 \mathrm{mg} / \mathrm{g}$ in dependence on the concentration of chloride solution. On the other hand, the lowest amount of bound chlorides was measured for the pure lime mortar VO that exhibited the maximum of bound chlorides of $\sim 11.0 \mathrm{mg} / \mathrm{g}$. Looking at the measured chloride binding isotherms, one can see that the amount of bound chlorides, which refers to the total amount of chlorides both chemically bound and physically adsorbed to the plasters hydration products, increases with an increase in the chloride concentration of the surrounding solution. From an engineering point of view, the nonlinearity of the chloride binding phenomenon is of a significant importance.

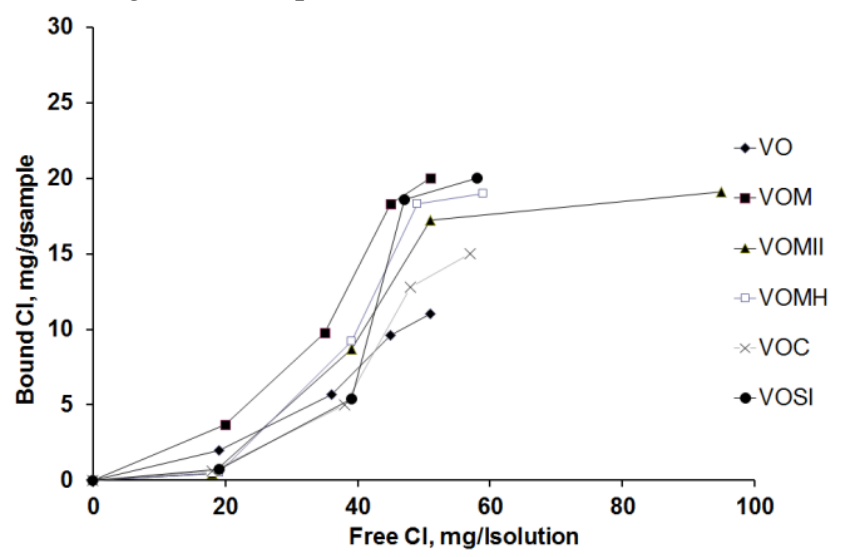

Fig. 7. Chloride binding isotherms of studied plasters

The significant differences in chloride binding capacity of the particular researched plasters can be assigned to the several factors, generally to the physical and chemical parameters of investigated materials. As the main physical parameters of porous material, the total open porosity and pore size distribution are of a particular importance. From this point of view, the high amount of bound chlorides in the studied renovation plaster can be simply explained because of it high porosity that was $54.6 \%$. From the chemical interaction point of view, the type of binder and mineral admixtures used in plasters composition has decisive role in chloride binding. It is known that chlorides react with monosulphate and hemicarbonate and transform partly to monochloroaluminate, commonly known as Friedel's salt [17]. When cement based materials originally exposed to high chloride concentration are subsequently exposed to chloride-free solution, a portion of the bound chlorides is released, but a significant portion remains irreversibly bound. Under these conditions, Friedel's salt may partially convert to Kuzel's salt [18]. Chlorides can also chemically and physically interact with $\mathrm{C}-\mathrm{S}-\mathrm{H}$ hydrates. Chlorides can either be present in a chemi/physically- absorbed layer on the hydrated calcium silicates, penetrate the $\mathrm{C}-\mathrm{S}-\mathrm{H}$ interlayer spaces, or be intimately bound in the $\mathrm{C}-\mathrm{S}-\mathrm{H}$ lattice [18]. The binding of chloride ions can be explained by an exchange mechanism between chloride ions from the pore solution and hydroxyl ions from the C-S-H layers. The $\mathrm{OH}-$ ion is loosely bound, permitting the $\mathrm{Cl}-$ ion to be substituted in the interlayer space and ensure the electroneutrality of the system. In general, it is accepted the $\mathrm{C}-\mathrm{S}-\mathrm{H}$ has a lower chloride binding ability than the AFm phase [19]. In lime based plasters, the chemical interaction of chlorides with hydrated products is based on reaction of calcium carbonate $\left(\mathrm{CaCO}_{3}\right)$, with $\mathrm{NaCl}$ that leads to the formation of highly hygroscopic $\mathrm{CaCl}_{2}$. In addition, chlorides can be accumulated in porous space and surface of particular hydrated products on physical principle considering the properties of materials inner 
structure. Here, the presence of salt can eventually lead to specific conditions for crystallization and material damage. At freezing temperatures, $\mathrm{NaCl}$ hydrates to hydrohalite $\left(\mathrm{NaCl} \cdot 2 \mathrm{H}_{2} \mathrm{O}\right)$ forming large, platy crystals that can potentially disrupt dense structure of silicate matrix.

\section{CONCLUSIONS}

The significant effect of the amount of accumulated chlorides on the water vapour adsorption capacity of salt contaminated plasters was found out. For plaster containing cement, the effect of salt content on the adsorption capacity was remarkable for higher $\mathrm{RH}$ values, typically from $\mathrm{RH}>0.7$. This we assigned to the deliquescence point of $\mathrm{NaCl}$ that has clear relation to the sharp increase in the mass of plasters containing salt exposed to higher RH. Plasters based on lime binder or lime-metakaolin blend exhibited salt influence on EMC values in the whole studied $\mathrm{RH}$ range. Also in this case, the deliquescence point of $\mathrm{NaCl}$ was visible. From the quantitative point of view, the highest water vapour sorption capacity had plaster VOS, having maximum of sorption isotherm at $0.21 \mathrm{~kg} / \mathrm{kg}$. This corresponds with its high binding capacity for chlorides that reached maximum at $20.0 \mathrm{mg} / \mathrm{g}$. Thus, applicability of plaster VOS in renovation of salt laden masonry was clearly proved. However, also plaster VOM accumulated high amount of chlorides that was around $19.5 \mathrm{mg} / \mathrm{g}$.

The theoretical model for the sorption capacity of salt laden materials was found to be applicable for estimation of sorption isotherms of porous building materials on silicate basis. The significant differences in chloride binding capacity of the particular researched plasters we assigned to the physical and chemical parameters of investigated materials, namely their porosity, type of binder, specific surface etc.

\section{Acknowledgments}

The authors greatly acknowledge the financial support provided by the Czech Science Foundation, under project No. 15-10591S, and by the Slovak Research and Development Agency under contract No. APVV-15-0631.

\section{REFERENCES}

1. Wu, M., Johannesson, B., Geiker, M. A Study of the Water Vapor Sorption Isotherms of Hardened Cement Pastes: Possible Pore Structure Changes at Low Relative Humidity and the Impact of on Isotherms Cement and Concrete Research 56 2014: pp. 97-105. https://doi.org/10.1016/j.cemconres.2013.11.008

2. Hansen, K.K. Sorption Isotherms - A Catalogue, Technical Report 162/86, TU Denmark, Lyngby, 1986.

3. Kumaran, M.K. A Thermal and Moisture Property Database for Common Building and Insulation Materials ASHRAE Transactions 112 2006: pp. 1-13.

4. McGregor, F., Heath, A., Shea, A., Lawrence, M. The Moisture Buffering Capacity of Unfired Clay Masonry Building and Environment 82 2014: pp. 599-607. https://doi.org/10.1016/j.buildenv.2014.09.027

5. Vololonirina, O., Countand, M., Perrin, B. Characterization of Hygrothermal Properties of Wood-Based Products - Impact of Moisture Content and
Temperature Construction and Building Materials 2014: pp. $223-233$.

https://doi.org/10.1016/j.conbuildmat.2014.04.014

6. Wortmann, F.J., Augustin, P., Popescu, C. Temperature Dependence of the Water-Sorption Isotherms of Wool Journal of Applied Polymer Science 79 2001: pp. 1054-1061.

7. Poyet, S., Charles, S. Temperature Dependence of the Sorption Isotherms of Cement-Based Materials: Heat of Sorption and Clausius-Clapeyron Formula Cement and Concrete Research 39 2009: pp. 1060-1067. https://doi.org/10.1016/j.cemconres.2009.07.018

8. Koronthalyova, O., Bagel, L., Kuliffayova, M., Ifka, T. Effect of Presence Salt on Hygric Performance of Ceramic Bricks Transport in Porous Media 107 2015: pp. $667-682$.

9. Lubelli, B., van Hees, R.P.J., $\quad$ Brocken, H.J.P. Experimental Research on Hygroscopic Behaviour of Porous Specimens Contaminated with Salts Construction and Building Materials 18 2004: pp. 339-348. https://doi.org/10.1016/j.conbuildmat.2004.02.007

10. Jiřičková, M., Černý, R. Chloride Binding in Building Materials Journal of Building Physics 29 2006: pp. 189-200.

11. Bahadur, R., Russel, L.M. Water Uptake Coefficients and Deliquescence of $\mathrm{NaCl}$ Nanoparticles at Atmospheric Relative Humidities from Molecular Dynamics Simulations The Journal of Chemical Physics 129 2008: pp. 094508.

12. Moropoulou, A., Karoglou, M., Giakoumaki, A., Krokida, M.K., Maroulis, Z.B., Saravacos, G.D. Drying Kinetics of Some Building Materials Brazilian Journal of Chemical Engineering 22 2005: pp. 203-208.

13. Koniorczyk, M., Wojciechowski, M. Influence of Salt on Desorption Isotherm and Hygral State of Cement Mortar Modelling Using Neural Networks Construction and Building Materials 23 2009: pp. 2988-2996. https://doi.org/10.1016/j.conbuildmat.2009.05.001

14. Price, C.A. Predicting Environmental Conditions to Minimize Salt Damage at the Tower of London: a Comparison of Two Approaches Environmental Geology 52 2007: pp. 369-374.

15. Dawoud, B., Aristov, Y. Experimental Study on the Kinetics of Water Vapor Sorption on Selective Water Sorbents, Silica Gel and Alumina under Typical Operating Conditions of Sorption Heat Pumps International Journal of Heat and Mass Transport 46 2003: pp. 273-281.

16. De Weerdt, K., Orsáková, D., Geiker, M.R. The Impact of Sulphate and Magnesium on Chloride Binding in Portland Cement Paste Cement and Concrete Research 65 2014: pp. $30-40$. https://doi.org/10.1016/j.cemconres.2014.07.007

17. Thomas, M.D.A., Hooten, R.D., Scott, A., Zibara, H. The Effect of Supplementary Cementitious Materials on Chloride Binding in Hardened Cement Paste Cement and Concrete Research 42 2012: pp. 1-7. https://doi.org/10.1016/j.cemconres.2011.01.001

18. Delagrave, A., Marchand, J., Olivier, J.P., Julien, S., Hazrati, K. Chloride Binding Capacity of Various Hydrated Cement Paste Systems Advanced Cement Based Materials 6 1997: pp. $28-35$. https://doi.org/10.1016/S1065-7355(97)90003-1

19. Yuan, Q., Shi, C., De Schutter, G., Audenaert, K., Deng, D. Chloride Binding of Cement-Based Materials Subjected to External Chloride Environment Construction and Building Materials 23 2009: pp. 1-13. https://doi.org/10.1016/j.conbuildmat.2008.02.004 